\title{
Prognostic role of Toll-like receptors in cancer: a meta-analysis
}

This article was published in the following Dove Press journal:

Therapeutics and Clinical Risk Management

\author{
Qingwen Wang' \\ Xiankai Zhang' \\ Tingting $\mathrm{XiaO}^{2}$ \\ Chenhua Pan' \\ Xing Liu ${ }^{3,4}$ \\ Yulan Zhao'
}

'Department of Physiology, School of Life Sciences, East China Normal University, Shanghai, People's Republic of China; '2Department of Botany, School of Life Sciences, Shanghai Normal University, Shanghai, People's Republic of China; ${ }^{3}$ Department of Central Laboratory Medicine, Shanghai Municipal Hospital of Traditional Chinese Medicine, Shanghai University of Traditional Chinese Medicine, Shanghai, People's Republic of China; ${ }^{4}$ Shanghai Biochip Corporation Ltd./National Engineering Center for Biochip at Shanghai, Shanghai, People's Republic of China
Correspondence: Xing Liu

Department of Central Laboratory Medicine, Shanghai Municipal Hospital of Traditional Chinese Medicine, Shanghai University of Traditional Chinese Medicine, Shanghai 20007I, People's Republic of China

Email liuxingII8@aliyun.com

Yulan Zhao

School of Life Sciences, East China Normal University, North Zhongshan Road \#3663, Shanghai City 20062,

People's Republic of China

Tel +86 2132530498

Fax +86 2132530498

Email ylzhao@imet.ecnu.edu.cn
Background: Recent studies have shown that Toll-like receptors (TLRs) may be associated with cancers. The aim of this meta-analysis is to summarize the predicting role of TLRs for survival in patients with a variety of carcinomas.

Materials and methods: Eligible studies were identified and assessed for quality through multiple search strategies. We collected data from studies investigating the relationship between the expression level of TLRs and survival in cancer patients. Studies were pooled and combined hazard ratios (HRs) of TLRs for survival were analyzed.

Results: A total of 24 studies, including 2,812 patients with various cancers, were identified for the meta-analysis. Importantly, this meta-analysis showed that higher expression levels of TLR4 or TLR7 in tumor tissues could predict poorer survival, with the pooled HR being 1.29 (95\% CI: 1.17, 1.42) and 1.71 (95\% CI: 1.38, 2.12), respectively. However, higher expression of TLR9 had no significant association with outcome as HR was 0.84 (95\% CI: 0.62, 1.115). Heterogeneity existed in TLR4 and TLR9 studies $(P$-value $<0.001)$ but not in TLR7 studies $(P$-value $>0.05)$.

Conclusion: The expression level of TLR4 or TLR7 in cancerous tissue may have a prognosis value in patients with various cancers.

Keywords: Toll-like receptors, cancers, prognosis

\section{Introduction}

Cancers constitute an enormous burden on modern society. About 14.1 million new cancer patients have been identified and 8.2 million deaths occurred in 2012 worldwide based on GLOBOCAN estimates. The burden is expected to increase because of the growing population and aging. ${ }^{1}$ In general, early diagnosis and specific therapy are crucial for better survival in cancer patients. Thereby, cancer biomarkers are important for improving outcome. Currently, some biomarkers have been applied in cancer diagnosis and monitored to evaluate the therapeutic effects, including genes or proteins related to cell proliferation, apoptosis, signal recognition, and transduction. However, cancer therapy is still a great challenge to date and precision medicine may be a potential trend to resolve it. Therefore, a cancer patient should be diagnosed more in detail and more biomarkers should be tested.

Toll-like receptors (TLRs) are a family of evolutionarily conserved pattern recognition receptors (PRRs), which participate in immunologic first-line host defense against pathogens by recognizing pathogen-associated molecular patterns (PAMPs). Different PRRs react with specific PAMPs, leading to distinct expression patterns, specific signaling pathways, and distinct antipathogen responses. Till now there are 13 TLRs described in mammals (ten receptors in humans and 12 in mice). Some TLRs reside at the plasma membrane, where they recognize molecular components located on the 
surface of pathogens. By contrast, others exist intracellularly, where they mediate recognition of nucleic acids. ${ }^{2}$ Recently, many studies revealed that TLRs play a cardinal role in the homeostasis of the human immune system. TLRs could recognize PAMPs and produce inflammatory cytokines to establish an effective defense system for the protection of the host. ${ }^{3,4}$ However, the abnormal activation of TLRs could jeopardize normal physiologic processes and may contribute to some diseases. ${ }^{5,6}$ Nowadays, more and more significant evidence suggested the important role for TLRs in human cancer, and inflammatory and immune diseases. ${ }^{7-9}$

Recent studies indicated that tumor cells had dysregulated expression of TLRs and TLRs signaling promoted tumor growth and immune evasion. ${ }^{10}$ Cammarota et al found that colorectal cancer (CRC) patients with higher TLR4 expression had a significantly increased risk of disease progression and those with very high levels of TLR4 in the tumor stroma relapsed significantly earlier than those with lower expression levels. ${ }^{11}$ However, Eiro et al reported that TLR4 expression by tumor cells was significantly associated with a lower rate of tumor recurrence in $\mathrm{CRC}^{12}$; whereas high TLR4 expression was significantly associated with a shortened relapsefree survival $(P=0.001)$ in cutaneous malignant melanoma (CMM). ${ }^{13}$ In addition, Grimm et al found that the survival in the highly expressing TLR7 and TLR8 subgroups was significantly poorer than that of the lowly expressing TLR7 and TLR8 subgroups in CRC. ${ }^{14}$ Therefore, to date, several TLRs were investigated in clinical prognosis studies and the results for a special TLR were inconsistent. It is timely and necessary for us to evaluate the overall risk of the expression of TLRs in patients with cancer.

\section{Materials and methods}

We performed this meta-analysis following the guidelines of the Meta-analysis of Observational Studies in Epidemiology group (MOOSE). ${ }^{15}$

\section{Search strategy}

To identify the relevant studies, we carefully searched online PubMed from 1966 to July 31, 2017. Two sets of keywords were used, namely "Toll-like receptors and cancer and prognosis" and "TLR, cancer, prognosis". The studies were regarded as eligible, as follows: 1) they studied the associations between TLRs and cancers; 2) they were designed as case-controlled ones, which means that they compare prognosis in patients with different TLR expression levels; 3 ) they reported data or figures about survival analysis and the follow-up duration cannot be less than 6 months. Articles were discarded when they met the following criteria: 1) no relationship with TLRs and survival; 2) review articles or letters; 3) key information missing (such as hazard ratio [HR] data or sample size). When duplicate studies were retrieved, the studies having reported HRs, or involving more patients (usually the latest one) were included in our analysis. Thus, the overlap between cohorts and overestimation of the overall HR could be avoided.

Information of all identified studies such as titles, abstracts, and full texts were carefully distinguished by two reviewers (Wang and Zhang) and double checked by Zhao. In case of key information missing, we sent emails to the authors for additional information for the meta-analytic calculations.

\section{Quality assessment}

According to a critical review checklist of the Dutch Cochrane Center proposed by MOOSE, we systematically assessed the quality of all the studies included. ${ }^{15}$ Six key items were used to assess the study quality, including 1) clear definition of study population; 2) clear definition of cancer type; 3) clear definition of study design; 4) clear definition of measurement of TLRs; 5) clear definition of outcome assessment, such as overall survival (OS), recurrence-free survival, or disease-free survival; 6) sufficient period of follow-up, not $<6$ months. If a study did not mention all these six points, it was excluded so as not to compromise the quality of the meta-analysis.

\section{Data extraction and statistical analysis}

Data from each of the included study were extracted independently by two authors (Wang and Zhang). Any inconsistencies in the data extraction were discussed with Zhao to reach consensus. The following information was collected from each eligible study: 1) publication details: first author's last name, publication year, country of origin; 2) characteristics of the studied population: sample size, age, sex, and type of disease; 3) study design: method to detect TLRs; follow-up duration; HR of elevated TLRs' expression for survival, as well as their $95 \% \mathrm{CI}$ and $P$-value. The simplest method consisted of the direct collection of HRs and their 95\% CI from the original literature, with a HR of more than 1 being associated with a poorer outcome. If the HR and $P$-value were not available in the literature, they were calculated from the numbers of patient deaths in each group. When information was only available as Kaplan-Meier curves, data were extracted from the graphical survival plots and estimation of the HR was then performed using the described method. ${ }^{16}$ 
Lower expressions of TLRs were chosen as baseline; if not, we will recalculate the HR by reciprocal.

\section{Statistical analysis}

Statistical heterogeneity across the studies was evaluated by the I-squared statistic and the significance of the heterogeneity was determined using the Cochran's Q test. A $P$-value of $<0.05$ was considered significant. A random-effect model (Der Simonian and Laird method) was used when heterogeneity was observed $(P<0.05)$, while the fixed-effect model was applied in the absence of between-study heterogeneity ( $P \geq 0.05)$. Publication bias was evaluated using the funnel plot with the Egger's bias indicator test. ${ }^{17}$ All statistical analyses were carried out by using Review Manager 5.3 (Cochrane, London, UK) and "Stata: Data Analysis and Statistical software" Version 12 (StataCorp LP, College Station, TX, USA).

\section{Results}

In PubMed, totally 200 publications were identified by the initial search strategy. After manually screening the titles, abstracts, and critical data, 149 records were excluded because they were review articles, letters, laboratory studies, or studies irrelevant to the current meta-analysis. Among 51 studies selected for detailed evaluation, nine of them about TLR2,
TLR3, or TLR 5 were excluded because there were insufficient studies for meta-analysis. Other 12 studies were excluded based on HR values missing. Ultimately, 24 studies $^{11-14,18-38}$ were included in our analysis, with four of them investigated two or three TLRs synchronously. Among them, 12, ${ }^{11-13,18-26}$ five, ${ }^{13,14,27-29}$ and eleven ${ }^{13,18,30-38}$ studies focused on TLR4, TLR7, and TLR9, respectively. The flow diagram of the study selection process is shown in Figure 1.

In Table 1, we summarized the main features of 24 eligible studies. The recruited 2,812 participants were globally from Italy, Spain, Finland, Croatia, Germany, France, Poland, USA, Korea, Japan, and China. The patients were suffering from a variety of carcinomas, including pancreatic cancer/pancreatic ductal adenocarcinoma, CRC, esophageal adenocarcinoma, hepatocellular carcinoma, CMM, ovarian epithelial cancers, breast cancer (BC), adenoid cystic carcinoma, oral squamous cell carcinoma/oral tongue squamous cell carcinoma, mucoepidermoid carcinoma, non-small-cell lung cancer, renal cell carcinoma, prostate cancer (ProC), and chronic lymphocytic leukemia (CLL). Immunohistochemistry was used in the majority of studies $(23 / 24)$ to measure the expression of TLRs. Although all of the studies applied dichotomy to compare the difference of survival, the TLR cutoff values were not consistent. Seven studies used

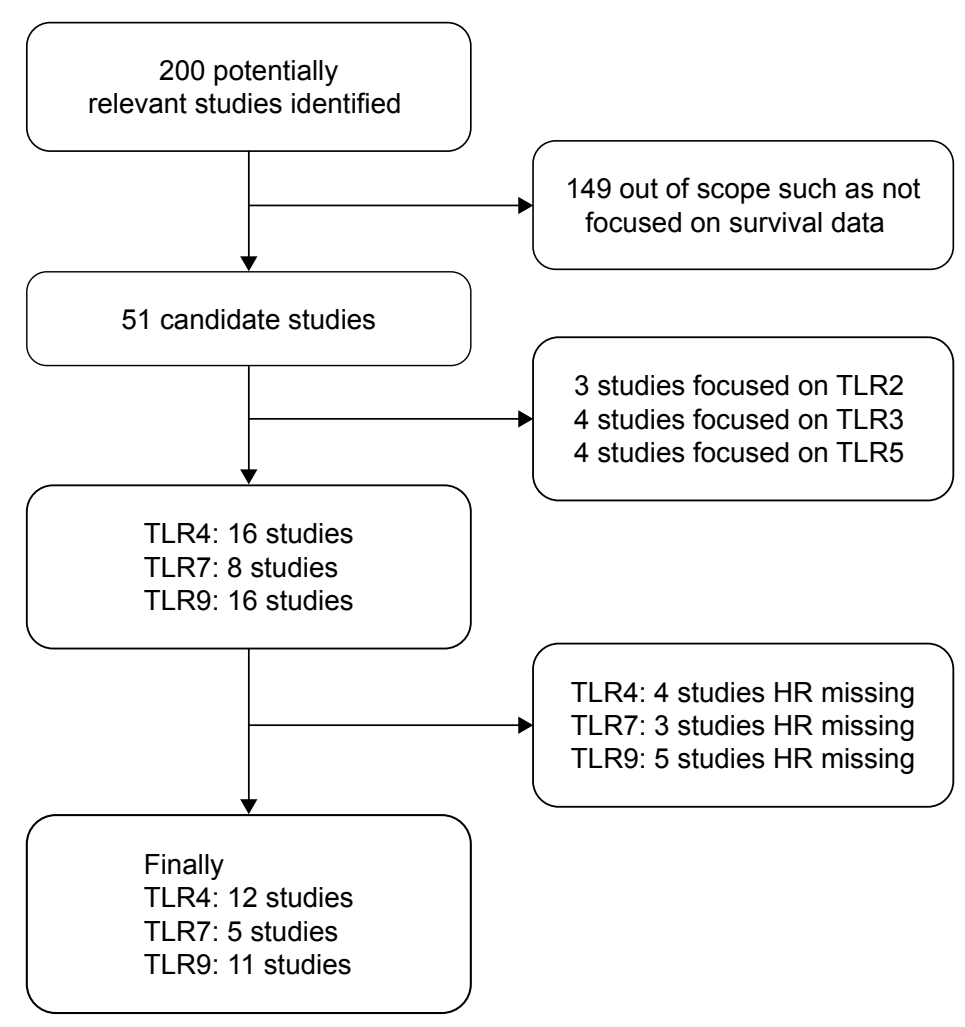

Figure I Flow diagram of the study selection process. Abbreviations: HR, hazard ratio; TLR, Toll-like receptor. 
Table I Summary table of the studies included in this meta-analysis

\begin{tabular}{|c|c|c|c|c|c|c|c|c|c|}
\hline Study year & $\begin{array}{l}\text { Origin of } \\
\text { population }\end{array}$ & Disease & $\begin{array}{l}\text { Subject } \\
\text { number }\end{array}$ & TLRs & Methods & Cutoff & $\begin{array}{l}\text { Survival } \\
\text { analysis }\end{array}$ & $\begin{array}{l}\text { HR } \\
\text { statistics }\end{array}$ & $\begin{array}{l}\text { Follow-up } \\
\text { (months) }\end{array}$ \\
\hline $\begin{array}{l}\text { Arja Jukkola-Vuorinen } \\
\text { et al, } 2009^{30}\end{array}$ & Finland & $B C$ & 141 & TLR9 & $\mathrm{IHC}$ & Low vs high & OS & $\mathrm{R}$ & 62.7 \\
\hline $\begin{array}{l}\text { Cammarota et al, } \\
2010^{\prime \prime}\end{array}$ & Italy & CRC & 53 & TLR4 & $\mathrm{IHC}$ & Median & DFS & $\mathrm{R}$ & $0-108$ \\
\hline $\begin{array}{l}\text { Eiró et al, } 2013^{12} \\
\text { Eiró et al, } 2013^{13}\end{array}$ & $\begin{array}{l}\text { Spain } \\
\text { Spain }\end{array}$ & $\begin{array}{l}\text { CRC } \\
\text { CMM }\end{array}$ & $\begin{array}{l}104 \\
30\end{array}$ & $\begin{array}{l}\text { TLR4 } \\
\text { TLR4, 7, } 9\end{array}$ & $\begin{array}{l}\mathrm{IHC} \\
\mathrm{IHC}\end{array}$ & $\begin{array}{l}\text { Median } \\
\text { Median }\end{array}$ & $\begin{array}{l}\text { RFS } \\
\text { RFS }\end{array}$ & $\begin{array}{l}\mathrm{SC} \\
\mathrm{SC}\end{array}$ & $\begin{array}{l}|2-3| 6 \\
\geq 36\end{array}$ \\
\hline Eiró et al, $2014^{18}$ & Spain & $\mathrm{HCC}$ & 30 & TLR4, 9 & $\mathrm{IHC}$ & Median & OS & SC & 60-204 \\
\hline Wang et al, $2010^{24}$ & Japan & CRC & 108 & TLR4 & $\mathrm{IHC}$ & Low vs high & DFS & $\mathrm{R}$ & - \\
\hline Ma et al, $2014^{22}$ & China & BC & 205 & TLR4 & $\mathrm{IHC}$ & Low vs high & DFS & $\mathrm{R}$ & $98(2-144)$ \\
\hline Grimm et al, $2010^{14}$ & Germany & CRC & 65 & TLR7 & $\mathrm{IHC}$ & Low vs high & OS & SC & 32 \\
\hline Ronkainen et al, 20I I ${ }^{35}$ & Finland & RCC & 152 & TLR9 & $\mathrm{IHC}$ & Negative vs positive & OS & $R$ & $90(0-209)$ \\
\hline Hirvonen et al, $2016^{28}$ & Finland & ACC & 32 & TLR7 & $\mathrm{IHC}$ & Median & OS & AP & - \\
\hline Huhta et al, $2016^{19}$ & Finland & EAC & 99 & TLR4 & $\mathrm{IHC}$ & Median & OS & SC & $36(0-288)$ \\
\hline Zhang et al, $2010^{25}$ & China & PDAC & 65 & TLR4 & $\mathrm{IHC}$ & Negative vs positive & OS & SC & $14(5-35)$ \\
\hline $\begin{array}{l}\text { Johanna Korvala et al, } \\
2014^{33}\end{array}$ & Finland & MEC & 60 & TLR9 & $\mathrm{IHC}$ & Low vs high & OS & SC & $66(2-303)$ \\
\hline Tuomela et al, $2012^{36}$ & Finland & BC & 231 & TLR9 & $\mathrm{IHC}$ & Low vs high & OS & SC & - \\
\hline Kauppila, 2014 & Finland & OTSCC & $|3|$ & TLR9 & $\mathrm{IHC}$ & Negative vs positive & OS & $\mathrm{R}$ & $119(24-298)$ \\
\hline Kauppila et al, 20I I 32 & USA & EAC & 85 & TLR9 & $\mathrm{IHC}$ & Negative vs positive & OS & SC & $17.5^{\circ}$ \\
\hline Kim et al, $2012^{20}$ & Korea & OEC & 123 & TLR4 & $\mathrm{IHC}$ & Negative vs positive & OS & SC & $43(3-140)$ \\
\hline Leppänen et al, 201734 & Finland & PC & 65 & TLR4, 9 & $\mathrm{IHC}$ & Low vs high & OS & AP & $21(1-60)$ \\
\hline Vaisanen, $2012^{37}$ & Finland & ProC & 242 & TLR9 & $\mathrm{IHC}$ & Negative vs positive & OS & $\mathrm{R}$ & - \\
\hline Własiuk et al, $2013^{38}$ & Poland & CLL & 41 & TLR9 & FCM & Low vs high & TFS & SC & 57 \\
\hline Petricevic et al, $2012^{23}$ & Croatia & BC & 133 & TLR4 & $\mathrm{IHC}$ & Negative vs positive & OS & SC & 60 \\
\hline Chatterjee et al, $2014^{27}$ & France & NSCLC & 352 & TLR7 & $\mathrm{IHC}$ & Low vs high & OS & $\mathrm{R}$ & - \\
\hline Ni et al, $2015^{29}$ & China & oscc & 166 & TLR7 & $\mathrm{IHC}$ & Low vs high & OS & $\mathrm{R}$ & - \\
\hline Zhe et al, $2016^{26}$ & China & $\mathrm{HCC}$ & 95 & TLR4 & $\mathrm{IHC}$ & Median & OS & $\mathrm{R}$ & $26.3(6-36)$ \\
\hline
\end{tabular}

Note: -, not available.

Abbreviations: ACC, adenoid cystic carcinoma; AP, author provided; BC, breast cancer; CLL, chronic lymphocytic leukemia; CMM, cutaneous malignant melanoma; CRC, colorectal cancer; DFS, disease-free survival; EAC, esophageal adenocarcinoma; FCM, flow cytometry; HCC, hepatocellular carcinoma; HR, hazard ratio; IHC, immunohistochemistry; MEC, mucoepidermoid carcinoma; NSCLC, non-small-cell lung cancer; OEC, ovarian epithelial cancer; OS, overall survival; OSCC, oral squamous cell carcinoma; OTSCC, oral tongue squamous cell carcinoma; PC, pancreatic cancer; PDAC, pancreatic ductal adenocarcinoma; ProC, prostate cancer; R, reported in the text; RCC, renal cell carcinoma; RFS, relapse-free survival; SC, survival curve; TFS, treatment-free survival; TLR, Toll-like receptor.

median as the cutoff value, seven studies compared positive to negative, and the other ten compared higher expression to lower expression. In addition, all of the studies were retrospective.

Subsequently, the heterogeneity of the included studies was assessed. There appeared to be heterogeneity between studies for TLR4 $(P<0.0001)$ and TLR9 $(P<0.00001)$ (Table 2). Therefore, a random model was applied to calculate

Table 2 Comparison of the predicting value of TLRs' expression in patients

\begin{tabular}{|c|c|c|c|}
\hline & TLR4 & TLR7 & TLR9 \\
\hline $\begin{array}{l}\text { Hazard ratio } \\
(95 \% \mathrm{Cl})\end{array}$ & $1.40(1.09,1.80)$ & $1.71(1.38,2.12)$ & $0.84(0.62,1.15)$ \\
\hline $\begin{array}{l}\text { Heterogeneity, } \\
P \text {-value }\end{array}$ & $<0.0001$ & 0.41 & $<0.0000$ I \\
\hline Bias, $P$-value & 0.410 & 0.957 & 0.757 \\
\hline Model & Random & Fixed & Random \\
\hline Subject number & $\mathrm{I}, \mathrm{I} \mid 4$ & 645 & 1,212 \\
\hline Study number & 12 & 5 & 11 \\
\hline
\end{tabular}

Abbreviation: TLR, Toll-like receptor. a pooled HR and its $95 \% \mathrm{CI}$. On the other hand, a fixed model was applied to calculate TLR7's pooled HRs and 95\% CI according to the homogeneity ( $P$-value $>0.05$ ). We found that higher expression levels of TLR4 and TLR7 predicted poorer survival, with the pooled HR being 1.29 (95\% CI: $1.17,1.42)$ and 1.71 (95\% CI: 1.38, 2.12) (Figure 2A and B). However, higher expression of TLR9 could not predict poorer survival (HR: 0.84; 95\% CI: 0.62, 1.115) (Figure 2C). In addition, considering the difference between solid tumors and leukemia, we reperformed a meta-analysis about TLR9 after deleting the study about CLL. The result remained not significant (HR: 0.81; 95\% CI: 0.58, 1.28). Furthermore, we also analyzed the association between the expression level of TLRs and OS alone. The data showed that higher expression levels of TLR4 and TLR7 predicted worse OS, with the pooled HR being 1.23 (95\% CI: 1.11, 1.37) and 1.78 (95\% CI: 1.36, 2.33), whereas higher expression of TLR9 had no prognostic value. Therefore, in a summary, the data suggested that TLR4 and TLR7 may have predictive value for cancer outcome. 


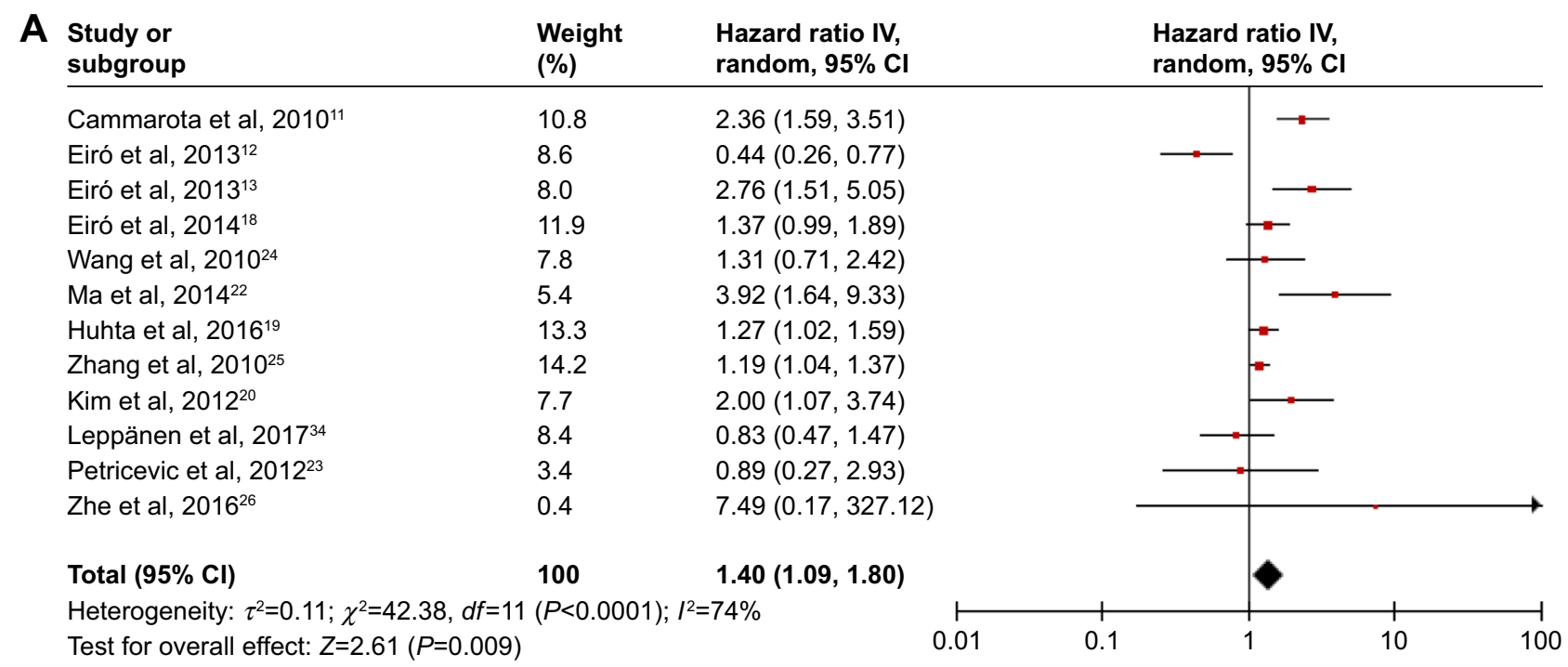

\begin{tabular}{|c|c|}
\hline $\begin{array}{l}\text { Study or } \\
\text { subgroup }\end{array}$ & $\begin{array}{l}\text { Weight } \\
(\%)\end{array}$ \\
\hline Eiró et al, $2013^{13}$ & 3.6 \\
\hline Grimm et al, $2010^{14}$ & 12.2 \\
\hline Hirvonen et al, $2016^{28}$ & 3.9 \\
\hline Chatterjee et al, $2014^{27}$ & 68.9 \\
\hline Ni et al, $2015^{29}$ & 11.5 \\
\hline Total $(95 \% \mathrm{Cl})$ & 100 \\
\hline \multicolumn{2}{|c|}{ Heterogeneity: $\tau^{2}=0.00 ; \chi^{2}=3.99, d f=4(P=0.41) ; I^{2}=0 \%$} \\
\hline \multicolumn{2}{|c|}{ Test for overall effect: $Z=4.91(P<0.00001)$} \\
\hline
\end{tabular}

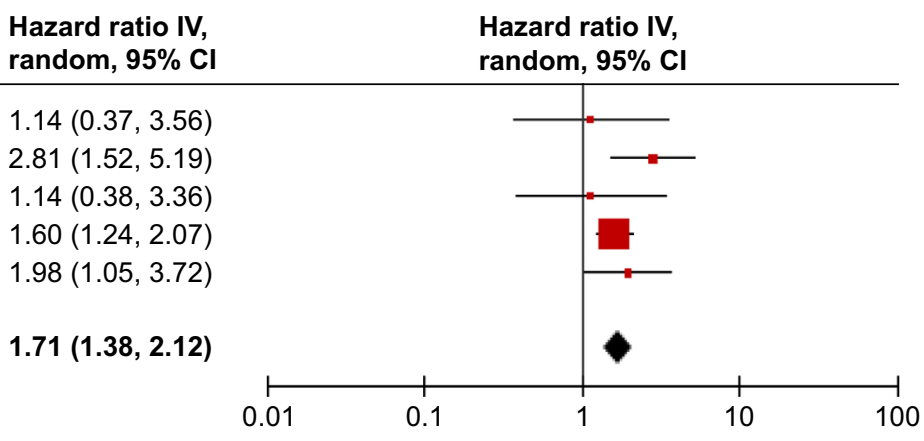

\begin{tabular}{|c|c|c|}
\hline $\begin{array}{l}\text { Study or } \\
\text { subgroup }\end{array}$ & $\begin{array}{l}\text { Weight } \\
(\%)\end{array}$ & $\begin{array}{l}\text { Hazard ratio IV, } \\
\text { random, } 95 \% \text { CI }\end{array}$ \\
\hline Arja Jukkola-Vuorinen et al, $2009^{30}$ & 5.2 & $2.71(0.92,8.00)$ \\
\hline Eiró et al, $2013^{13}$ & 6.2 & $0.74(0.29,1.88)$ \\
\hline Eiró et al, $2014^{18}$ & 11.1 & $1.31(0.85,2.02)$ \\
\hline Ronkainen et al, $2011^{35}$ & 8.7 & $0.42(0.22,0.81)$ \\
\hline Johanna Korvala et al, $2014^{33}$ & 6.6 & $0.25(0.10,0.60)$ \\
\hline Tuomela et al, $2012^{36}$ & 6.4 & $0.20(0.08,0.50)$ \\
\hline Kauppila et al, $2015^{31}$ & 9.9 & $1.81(1.05,3.11)$ \\
\hline Kauppila et al, $2011^{32}$ & 13.6 & $1.22(1.02,1.45)$ \\
\hline Leppäneu et al, $2017^{34}$ & 9.1 & $0.32(0.18,0.60)$ \\
\hline Vaisanen et al, $2012^{37}$ & 8.9 & $2.27(1.20,0.96)$ \\
\hline Własiuk et al, $2013^{38}$ & 14.1 & $0.88(0.81,0.96)$ \\
\hline Total $(95 \% \mathrm{Cl})$ & 100 & $0.84(0.62,1.15)$ \\
\hline
\end{tabular}

Figure 2 Forest plots of studies evaluating hazard ratios of higher expression of TLR4 (A), TLR7 (B), and TLR9 (C) as compared to lower expression in various cancers. Abbreviation: TLR, Toll-like receptor.

Finally, as shown in Figure 3 and Table 2, publication bias of the included studies was evaluated by funnel plots and Egger's tests. In TLR4, TLR7, and TLR9 meta-analysis, the $P$-values of Egger's regression intercepts were 0.410,
0.957 , and 0.757 , respectively. There was no publication bias existing in the studies because the funnel plots were almost symmetric and the $P$-values of Egger's regression were more than 0.05 . 
A

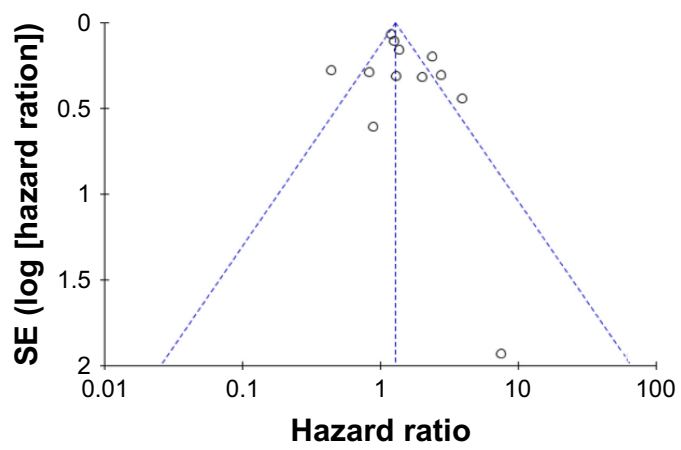

B

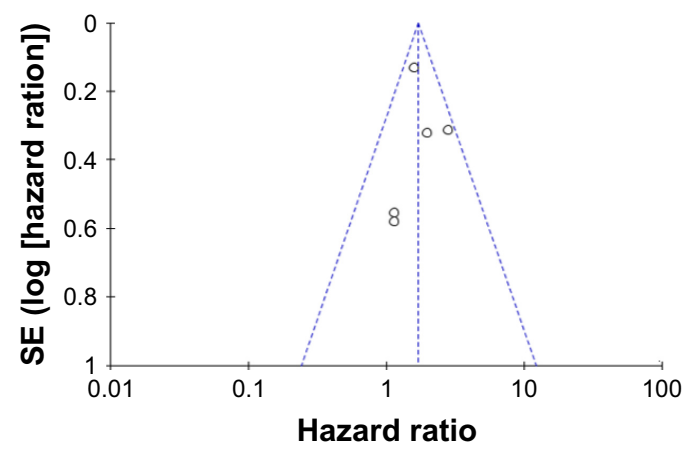

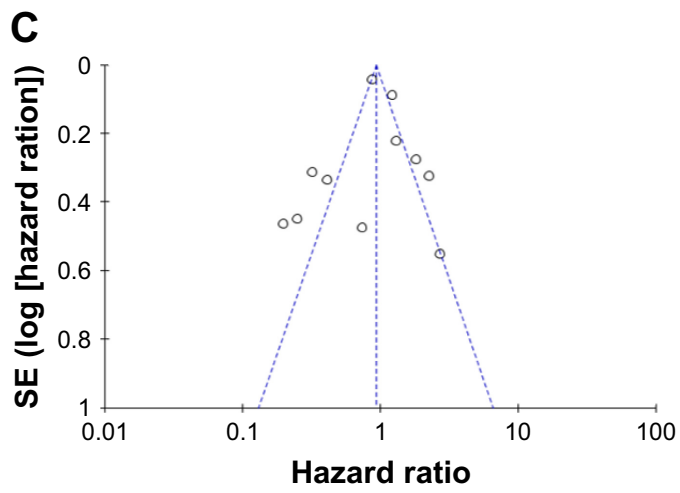

Figure 3 Funnel plots of studies included in the meta-analyses of TLR4 (A), TLR7 (B), and TLR9 (C).

Abbreviations: SE, standard error; TLR, Toll-like receptor.

\section{Discussion}

This systemic review and meta-analysis, which recruited 24 studies and 2,812 patients, showed that higher expression of TLR4 or TLR7 did indeed predict poor survival in patients with a variety of carcinomas. The analysis of TLR9, however, could not get the significant results.

In general, the meta-analysis as performed in this study had a number of inherent limitations, so the conclusion should be tempered for several reasons. First, although the pooled risks of TLR4 and TLR7 were statistically significant, they were not strong, with HRs of 1.4 and 1.71, respectively. Empirically, HR $>2$ is considered strongly predictive. ${ }^{39}$ Second, as only five studies were included for analysis with a relatively sample size of 645 , the meta-analysis result of TLR7 was less powerful. More studies should be conducted in future to evaluate the prognostic value of TLRs in cancers. Third, one study detected the total expression of TLR9 in CLL, which was different from other malignant solid tumors.

Marked heterogeneity of subjects existed in TLR4 and TLR9 groups. The heterogeneity of the populations was probably due to the difference in baseline characteristics of patients (age, stage, sex, race, or country), the duration of follow-up, cancer type, the cutoff value of TLRs, and so on. For example, several studies utilized median expression as the cutoff, while others used positive vs negative or low vs high. Even for those studies using median value in their laboratory or hospital as the cutoff value, the accurate values were different, and thereby, this analysis could not provide a clear clue about how high is high. As such differences might have a residual confounding effect within these studies, we attempted to minimize the effect by using a random-effect model. In addition, the prognostic value may also be weakened because all cancers were grouped together without identifying some particular cancers having increased exposure to commensal bacteria. For routine clinical application in future, more studies should be conducted and the above-mentioned problems should be solved by further experimental studies.

Our data demonstrated that TLR4 and TLR7 were promising biomarkers of cancers, while TLR9 may not be appropriate for monitoring clinical outcome. Other than TLR4, TLR7, and TLR9, researchers also reported other TLRs related to cancers. Elevated expression of some TLRs has been reported in many tumor cells and tissues. ${ }^{5}$ Ironically, overexpression of TLRs has been paradoxically found in 
many tumor cases. Grimm et al found that high expression of TLR8 was an independent prognostic factor for worse outcome in multivariate analysis. ${ }^{14}$ Makinen et al found that high or strong TLR2 expression was correlated with deeper tumor invasion, whereas negative or mild TLR5 expression predicted poor disease-specific survival. ${ }^{40}$ Gonzalez-Reyes et al reported that tumors with high TLR3 expression were significantly associated with higher probability of metastasis in $\mathrm{BC}$ and with higher probability of biochemical recurrence in ProC. ${ }^{41,42}$ The above studies suggested that the other TLRs may also play predicting roles in various cancers. For the current meta-analysis, however, we did not conduct further analysis because of the limited study number.

Although dysregulation of TLRs was found in many malignant tumors, the biologic function of TLRs in tumor formation and development remains obscure because of the limited duration of research after they were identified in the latest decade. Interestingly, despite divergent ligands and receptors, two major pathways are used by TLR family, one is mediated by myeloid differentiation primary-response protein 88 (MyD88) and the other is independent of MyD88. All TLRs except TLR3 use a common signaling pathway through the adaptor molecule MyD88.43,44 TLRs that are activated by their individual ligands could recruit MyD88 and subsequently activate the downstream targets, including nuclear factor of kappa B, mitogen-associated protein kinase, and interferon regulatory factors. ${ }^{2}$ Furthermore, recently, numerous studies have demonstrated that TLRs could be involved in antitumor or protumor responses. ${ }^{45,46}$ For example, TLR4-deficient mice have showed enhanced tumorigenesis in inducible model of lung cancer, skin cancer, and BC. Injection of TLR4 agonists, such as OM-174 and OK-132, could repress tumor formation in mice. Such results suggested that TLR4 may have antitumor effects. However, other studies about cancer cells showed that TLR4 stimulation could induce tumor cell proliferation and suppress apoptosis. Hence, to date, the accurate effects of TLRs in cancer still remain unclear and more experiments should be conducted in the future.

\section{Conclusion}

Our meta-analysis, representing a quantified synthesis of all published studies, has shown that the elevated TLR4 and TLR7 expression is significantly associated with poor survival in patients with various types of carcinoma. More clinical investigations should be conducted before TLRs can be implemented in the routine clinical management of cancer.

\section{Acknowledgments}

The analysis was sponsored by Natural Science Foundation of Shanghai (17ZR1408000), National Natural Science Foundation of China (81502059), Shanghai Rising-Star Program (16QB1402900), and Science and Technology Development Foundation of Pudong New District, Shanghai, China (PKJ2015-S29).

\section{Disclosure}

The authors report no conflicts of interest in this work.

\section{References}

1. Torre LA, Bray F, Siegel RL, Ferlay J, Lortet-Tieulent J, Jemal A. Global cancer statistics, 2012. CA Cancer J Clin. 2015;65(2):87-108.

2. Akira S, Uematsu S, Takeuchi O. Pathogen recognition and innate immunity. Cell. 2006;124(4):783-801.

3. Shankaran V, Ikeda H, Bruce AT, et al. IFNgamma and lymphocytes prevent primary tumour development and shape tumour immunogenicity. Nature. 2001;410(6832):1107-1111.

4. Kawai T, Akira S. The role of pattern-recognition receptors in innate immunity: update on Toll-like receptors. Nat Immunol. 2010;11(5): 373-384.

5. Ey S, Ouchi T. The application of Toll like receptors for cancer therapy. J Int J Biol Sci. 2010;6(7):675-681.

6. Keogh B, Parker AE. Toll-like receptors as targets for immune disorders. Trends Pharmacol Sci. 2011;32(7):435-442.

7. Liew FY, Xu D, Brint EK, O'Neill LA. Negative regulation of toll-like receptor-mediated immune responses. Nat Rev Immunol. 2005;5(6):446-458.

8. Taniguchi N, Kawahara K, Yone K, et al. High mobility group box chromosomal protein 1 plays a role in the pathogenesis of rheumatoid arthritis as a novel cytokine. Arthritis Rheum. 2003;48(4):971-981.

9. So EY, Ouchi T. The application of Toll like receptors for cancer therapy. Int J Biol Sci. 2010;6(7):675-681.

10. Iwasaki A, Medzhitov R. Toll-like receptor control of the adaptive immune responses. Nat Immunol. 2004;5(10):987-995.

11. Cammarota R, Bertolini V, Pennesi G, et al. The tumor microenvironment of colorectal cancer: stromal TLR-4 expression as a potential prognostic marker. J Transl Med. 2010;8:112.

12. Eiró N, González L, González LO, et al. Toll-like receptor-4 expression by stromal fibroblasts is associated with poor prognosis in colorectal cancer. J Immunother. 2013;36(6):342-349.

13. Eiró N, Ovies C, Fernandez-Garcia B, et al. Expression of TLR3, 4, 7 and 9 in cutaneous malignant melanoma: relationship with clinicopathological characteristics and prognosis. Arch Dermatol Res. 2013;305(1):59-67.

14. Grimm M, Kim M, Rosenwald A, et al. Toll-like receptor (TLR) 7 and TLR8 expression on CD133+ cells in colorectal cancer points to a specific role for inflammation-induced TLRs in tumourigenesis and tumour progression. Eur J Cancer. 2010;46(15):2849-2857.

15. Stroup DF, Berlin JA, Morton SC, et al. Meta-analysis of observational studies in epidemiology: a proposal for reporting. Meta-analysis Of Observational Studies in Epidemiology (MOOSE) group. JAMA. 2000;283(15):2008-2012.

16. Parmar MK, Torri V, Stewart L. Extracting summary statistics to perform meta-analyses of the published literature for survival endpoints. Stat Med. 1998;17(24):2815-2834.

17. Egger M, Davey Smith G, Schneider M, Minder C. Bias in meta-analysis detected by a simple, graphical test. BMJ. 1997;315(7109):629-634.

18. Eiró N, Altadill A, Juárez LM, et al. Toll-like receptors 3, 4 and 9 in hepatocellular carcinoma: relationship with clinicopathological characteristics and prognosis. Hepatol Res. 2014;44(7):769-778. 
19. Huhta H, Helminen O, Lehenkari PP, Saarnio J, Karttunen TJ, Kauppila JH. Toll-like receptors 1, 2, 4 and 6 in esophageal epithelium, Barrett's esophagus, dysplasia and adenocarcinoma. Oncotarget. 2016;7(17):23658-23667.

20. Kim KH, Jo MS, Suh DS, et al. Expression and significance of the TLR4/MyD88 signaling pathway in ovarian epithelial cancers. World J Surg Oncol. 2012;10:193.

21. Leppänen J, Helminen O, Huhta H, et al. High toll-like receptor (TLR) 9 expression is associated with better prognosis in surgically treated pancreatic cancer patients. Virchows Archiv. 2017;470(4):401-410.

22. Ma FJ, Liu ZB, Hu X, et al. Prognostic value of myeloid differentiation primary response 88 and Toll-like receptor 4 in breast cancer patients. PLoS One. 2014;9(10):e111639.

23. Petricevic B, Vrbanec D, Jakic-Razumovic J, et al. Expression of Toll-like receptor 4 and beta 1 integrin in breast cancer. Med Oncol. 2012;29(2):486-494.

24. Wang EL, Qian ZR, Nakasono M, et al. High expression of Toll-like receptor 4/myeloid differentiation factor 88 signals correlates with poor prognosis in colorectal cancer. Br J Cancer. 2010;102(5):908-915.

25. Zhang JJ, Wu HS, Wang L, Tian Y, Zhang JH, Wu HL. Expression and significance of TLR4 and HIF-1alpha in pancreatic ductal adenocarcinoma. World J Gastroenterol. 2010;16(23):2881-2888.

26. Zhe Y, Li Y, Liu D, Su DM, Liu JG, Li HY. Extracellular HSP70peptide complexes promote the proliferation of hepatocellular carcinoma cells via TLR2/4/JNK1/2MAPK pathway. Tumour Biol. 2016;37(10):13951-13959.

27. Chatterjee S, Crozet L, Damotte D, et al. TLR7 promotes tumor progression, chemotherapy resistance, and poor clinical outcomes in non-small cell lung cancer. Cancer Res. 2014;74(18):5008-5018.

28. Hirvonen K, Bäck L, Haglund C, et al. Toll-like receptor 5 and 7 expression in adenoid cystic carcinoma of major salivary glands. Tumour Biol. 2016;37(8):10959-10964.

29. Ni YH, Ding L, Zhang DY, Hou YY, Huang X, Hu Q. Distinct expression patterns of Toll-like receptor 7 in tumour cells and fibroblast-like cells in oral squamous cell carcinoma. Histopathology. 2015;67(5):730-739.

30. Jukkola-Vuorinen A, Rahko E, Vuopala KS, et al. Toll-like receptor-9 expression is inversely correlated with estrogen receptor status in breast cancer. J Innate Immun. 2009;1(1):59-68.

31. Kauppila JH, Korvala J, Siirilä K, et al. Toll-like receptor 9 mediates invasion and predicts prognosis in squamous cell carcinoma of the mobile tongue. J Oral Pathol Med. 2015;44(8):571-577.

32. Kauppila JH, Takala H, Selander KS, Lehenkari PP, Saarnio J, Karttunen TJ. Increased Toll-like receptor 9 expression indicates adverse prognosis in oesophageal adenocarcinoma. Histopathology. 2011;59(4):643-649.
33. Korvala J, Harjula T, Siirilä K, et al. Toll-like receptor 9 expression in mucoepidermoid salivary gland carcinoma may associate with good prognosis. J Oral Pathol Med. 2014;43(7):530-537.

34. Leppänen J, Helminen O, Huhta H, et al. High toll-like receptor (TLR) 9 expression is associated with better prognosis in surgically treated pancreatic cancer patients. Virchows Arch. 2017;470(4):401-410.

35. Ronkainen H, Hirvikoski P, Kauppila S, et al. Absent Toll-like receptor-9 expression predicts poor prognosis in renal cell carcinoma. J Exp Clin Cancer Res. 2011;30:84.

36. Tuomela J, Sandholm J, Karihtala P, et al. Low TLR9 expression defines an aggressive subtype of triple-negative breast cancer. Breast Cancer Res Treat. 2012;135(2):481-493.

37. Väisänen MR, Jukkola-Vuorinen A, Vuopala KS, Selander KS, Vaarala MH. Expression of Toll-like receptor-9 is associated with poor progression-free survival in prostate cancer. Oncol Lett. 2013;5(5): 1659-1663.

38. Własiuk P, Tomczak W, Zając M, Dmoszyńska A, Giannopoulos K. Total expression of HLA-G and TLR-9 in chronic lymphocytic leukemia patients. Hum Immunol. 2013;74(12):1592-1597.

39. Hayes DF, Isaacs C, Stearns V. Prognostic factors in breast cancer: current and new predictors of metastasis. J Mammary Gland Biol Neoplasia. 2001;6(4):375-392.

40. Mäkinen LK, Atula T, Häyry V, et al. Predictive role of Toll-like receptors 2, 4, and 9 in oral tongue squamous cell carcinoma. Oral Oncol. 2015;51(1):96-102.

41. González-Reyes S, Marín L, González L, et al. Study of TLR3, TLR4 and TLR9 in breast carcinomas and their association with metastasis. BMC Cancer. 2010;10:665.

42. González-Reyes S, Fernández JM, González LO, et al. Study of TLR3, TLR4, and TLR9 in prostate carcinomas and their association with biochemical recurrence. Cancer Immunol Immunother. 2011;60(2):217-226.

43. Bryant CE, Symmons M, Gay NJ. Toll-like receptor signalling through macromolecular protein complexes. Mol Immunol. 2015;63(2): $162-165$.

44. Kopp E, Medzhitov R. Recognition of microbial infection by Toll-like receptors. Curr Opin Immunol. 2003;15(4):396-401.

45. Dajon M, Iribarren K, Cremer I. Toll-like receptor stimulation in cancer: a pro- and anti-tumor double-edged sword. Immunobiology. 2017; 222(1):89-100.

46. Moradi-Marjaneh R, Hassanian SM, Fiuji H, et al. Toll like receptor signaling pathway as a potential therapeutic target in colorectal cancer. J Cell Physiol. 2018;233(8):5613-5622.
Therapeutics and Clinical Risk Management

\section{Publish your work in this journal}

Therapeutics and Clinical Risk Management is an international, peerreviewed journal of clinical therapeutics and risk management, focusing on concise rapid reporting of clinical studies in all therapeutic areas, outcomes, safety, and programs for the effective, safe, and sustained use of medicines. This journal is indexed on PubMed Central, CAS,
Dovepress

EMBase, Scopus and the Elsevier Bibliographic databases. The manuscript management system is completely online and includes a very quick and fair peer-review system, which is all easy to use. Visit http://www.dovepress.com/testimonials.php to read real quotes from published authors. 